\section{OPEN ACCESS}

Edited by:

Jean-Claude Lacaille, Université de Montréal, Canada

Reviewed by:

Kurt Gottmann, Heinrich Heine University Düsseldorf, Germany

Wayne S. Sossin, McGill University, Canada

*Correspondence: Thomas Dresbach thomas.dresbach@ med.uni-goettingen.de

Received: 22 July 2019 Accepted: 31 October 2019 Published: 15 November 2019

Citation:

Viotti JS and Dresbach T (2019) Differential Effect on Hippocampal Synaptic Facilitation by the Presynaptic Protein Mover. Front. Synaptic Neurosci. 11:30. doi: 10.3389/fnsyn.2019.00030

\title{
Differential Effect on Hippocampal Synaptic Facilitation by the Presynaptic Protein Mover
}

Julio S. Viotti and Thomas Dresbach*

Institute of Anatomy and Embryology, University Medical Center Göttingen, Georg-August University of Göttingen, Göttingen, Germany

Neurotransmitter release relies on an evolutionarily conserved presynaptic machinery. Nonetheless, some proteins occur in certain species and synapses, and are absent in others, indicating that they may have modulatory roles. How such proteins expand the power or versatility of the core release machinery is unclear. The presynaptic protein Mover/TPRGL/SVAP30 is heterogeneously expressed among synapses of the rodent brain, suggesting that it may add special functions to subtypes of presynaptic terminals. Mover is a synaptic vesicle-attached phosphoprotein that binds to Calmodulin and the active zone scaffolding protein Bassoon. Here we use a Mover knockout mouse line to investigate the role of Mover in the hippocampal mossy fiber (MF) to CA3 pyramidal cell synapse and Schaffer collateral to CA1. While Schaffer collateral synapses were unchanged by the knockout, the MFs showed strongly increased facilitation. The effect of Mover knockout in facilitation was both calcium- and age-dependent, having a stronger effect at higher calcium concentrations and in younger animals. Increasing cyclic adenosine monophosphate (CAMP) levels by forskolin equally potentiated both wildtype and knockout MF synapses, but occluded the increased facilitation observed in the knockout. These discoveries suggest that Mover has distinct roles at different synapses. At MF terminals, it acts to constrain the extent of presynaptic facilitation.

Keywords: synaptic transmission, short-term plasticity, hippocampus, CA3, mossy fiber, presynapse

\section{INTRODUCTION}

The molecular machinery mediating neurotransmitter release is strongly conserved throughout evolution: $\mathrm{Ca}^{2+}$ triggers exocytosis of neurotransmitter from synaptic vesicles (SVs) in less than a millisecond by binding to Synaptotagmin, which together with Complexins activates a core fusion machinery composed of SNAREs and SV proteins (Südhof, 2013). These events are confined to specialized sites of the presynaptic plasma membrane, called active zones, by a network of proteins including RIMs, RIM binding proteins, Munc13s, $\alpha$-liprins and CAST/ERC proteins. One of the ways by which these scaffolding molecules act is that RIMs recruit both calcium channels and Munc13s, which make SVs tethered at the active zone fusion competent (Südhof, 2012; Imig et al., 2014; Acuna et al., 2016). The physical and functional interactions of all these proteins represent an evolutionarily conserved machinery mediating regulated neurotransmitter release at active zones. The evolutionarily conserved $\mathrm{Ca}^{2+}$ binding proteins Calmodulin and Synaptotagmin-7 
further refine the machinery by regulating presynaptic plasticity such as short-term depression and short-term enhancement to transmitter release (Junge et al., 2004; Jackman et al., 2016).

Piccolo/Aczonin and Bassoon are particularly large active zone scaffolding molecules, consisting of approximately 5000 and 4000 amino acids, respectively (Cases-Langhoff et al., 1996; tom Dieck et al., 1998; Wang et al., 1999). Piccolo is evolutionarily related to RIM (Bruckner et al., 2012) and shares 10 PiccoloBassoon homology regions with Bassoon (tom Dieck et al., 1998; Gundelfinger et al., 2016). Piccolo and Bassoon do not seem to be essential for the process of transmitter release (Hallermann et al., 2010; Mukherjee et al., 2010; Mendoza Schulz et al., 2014; Butola et al., 2017; Parthier et al., 2018), but maintain synaptic integrity by reducing the degradation of presynaptic molecules by proteasomes and autophagy (Waites et al., 2013; Okerlund et al., 2017). As scaffolding proteins that appear very early at nascent active zones and bind a large number of proteins they may also act to recruit regulatory molecules to active zones (Fejtova and Gundelfinger, 2006; Schoch and Gundelfinger, 2006; Gundelfinger et al., 2016).

In a yeast-2-hybrid assay we identified the SV phosphoprotein Mover - also called SVAP-30 and TPRGL (Burré et al., 2006; Antonini et al., 2008) - as a binding partner for Bassoon (Kremer et al., 2007; Ahmed et al., 2013). Mover is a small, 266 amino acid, protein that does not appear to have orthologs in the nematode Caenorhabditis elegans and the fruit fly Drosophila, suggesting that it is not required for the basic functions of the transmitter release machinery. In the rodent brain, its distribution is remarkably heterogeneous. For example, inhibitory synapses in the hippocampal CA3 region lack Mover, while excitatory synapses in the same region contain Mover (Kremer et al., 2007). Quantitative analysis revealed that the levels of Mover relative to the number of SVs vary among synapses throughout the brain (Wallrafen and Dresbach, 2018). These observations suggest that Mover may perform regulatory functions at certain synapses. To test how the absence of Mover affects synaptic transmission, we investigated two different hippocampal synapses. We assumed that synapse function would not be abolished, but a modulatory role would emerge. We found that the absence of Mover affects short-term plasticity in the hippocampal CA3 but not in CA1. We show that this effect is age- and $\mathrm{Ca}^{2+}$-dependent, and interacts with the cyclic adenosine monophosphate (cAMP) pathway in the mossy fiber (MF) synapses.

\section{MATERIALS AND METHODS}

\section{KO Generation, Genotyping, and Confirmation}

All animal experiments were performed in accordance with the guidelines for the welfare of experimental animals issued by the State Government of Lower Saxony, Germany. All mice (Mus musculus) were bred and maintained at the central animal facility of the University Medical Center, Göttingen. Embryonic stem cells (129/Ola) harboring the recombined Mover locus were generated by PolyGene (Switzerland), and injected into blastocysts. Mice with the targeted locus were crossed with a Flp deleter line to remove the Neo cassette. The resulting conditional knockout mice were crossed with mice expressing Cre recombinase under the E2A promoter to generate a global Mover knockout (Akula et al., 2019). Knockout (KO) animals were compared to their wildtype (WT) littermates.

Mice were routinely genotyped by PCR using genomic DNA extracted from tail biopsies using a DNA extraction kit from NextTec (Germany). For amplification the following oligonucleotide primers were used: forward primer P1 (5'-CCAATCACAAGGCGAACGAG-3'); forward primer P2 (5'-CATTCAGTGGGACAAGCAGA-3'); reverse primer P3 ( $5^{\prime}$-CTTGGATCAGGAGAGCCTTG- $3^{\prime}$ ). The PCR reaction was carried out for 40 cycles with denaturation at $95^{\circ} \mathrm{C}$ for $30 \mathrm{~s}$, annealing at $56^{\circ} \mathrm{C}$ for $1 \mathrm{~min}$, and extension at $72^{\circ} \mathrm{C}$ for $1 \mathrm{~min}$. WT and $\mathrm{KO}$ animals were identified by the presence of a specific $867 \mathrm{bp}$ and a $697 \mathrm{bp}$ band, respectively. Initially, the KO was verified by purifying and sequencing the $697 \mathrm{bp}$ band.

For immunohistochemical confirmation of the knockout of Mover, mice were perfused with $4 \%$ paraformaldehyde and had their hippocampi sectioned with $50 \mu \mathrm{m}$ thickness. Commercially available anti-Mover and anti-Synaptophysin antibodies (Synaptic Systems, Germany) were used in combination with Cy2 and Cy5 secondary antibodies (Dianova, Germany). Stainings were visualized by epifluorescence through an Observer Z1 inverted microscope (Zeiss, Germany).

\section{Slice Preparation and Electrophysiology}

Acute transverse hippocampal slices $400 \mu \mathrm{m}$ thick were prepared from male and female 18-22 days old mice unless otherwise noted. Hippocampi were isolated and cut in a Thermo Scientific HM650V vibratome in a cutting solution containing (in $\mathrm{mM}$ ): 215 sucrose, $2.5 \mathrm{KCl}, 20$ glucose, $26 \mathrm{NaHCO}_{3}, 1.6 \mathrm{NaH}_{2} \mathrm{PO}_{4}$, $1 \mathrm{CaCl}_{2}, 4 \mathrm{MgCl}_{2}$, and $4 \mathrm{MgSO}_{4}$. After sectioning, the slices were incubated for $30 \mathrm{~min}$ in a solution comprised of $50 \%$ cutting solution and $50 \%$ recording solution, which contained (in mM): $124 \mathrm{NaCl}, 2.5 \mathrm{KCl}, 26 \mathrm{NaHCO}_{3}, 1 \mathrm{NaH}_{2} \mathrm{PO}_{4}, 2.5$ $\mathrm{CaCl}_{2}, 1.3 \mathrm{MgSO}_{4}$, and 10 glucose; $300 \mathrm{mOsm} / \mathrm{kg}$. Recording solution for whole-cell patch clamp recordings, was comprised of (in $\mathrm{mM}$ ): $119 \mathrm{NaCl}, 2.5 \mathrm{KCl}, 26 \mathrm{NaHCO}_{3}, 1 \mathrm{NaH}_{2} \mathrm{PO}_{4}$, $4 \mathrm{CaCl}_{2}, 4 \mathrm{MgSO}_{4}$, and 10 glucose; $300 \mathrm{mOsm} / \mathrm{kg}$. After the aforementioned $30 \mathrm{~min}$ incubation, the mixed solution was changed to $100 \%$ recording solution. After changing of solution, slices were incubated for at least $60 \mathrm{~min}$ at room temperature. All solutions were continuously gassed with carbogen $\left(95 \% \mathrm{O}_{2}, 5 \%\right.$ $\mathrm{CO}_{2}$ ) and were recorded at $27 \pm 0.2^{\circ} \mathrm{C}$.

Excitatory post synaptic potentials (EPSPs) and receptor excitatory postsynaptic currents (EPSCs) were recorded using a HEKA EPC-10 amplifier connected to a chlorided silver wire in a borosilicate glass pipette. Recording pipettes had 0.5$1.5 \mathrm{M} \Omega$ pipette resistance and were filled with $1 \mathrm{M} \mathrm{NaCl}$ for extracellular recordings, and 2.0-4.0 $\mathrm{M} \Omega$ for whole-cell recordings with a solution containing (in $\mathrm{mM}$ ): 123 Cs-gluconate, $8 \mathrm{NaCl}, 10$ HEPES, 10 Glucose, 10 BAPTA, 5 ATP-Mg, 0.4 GTP$\mathrm{Na} ; 300 \mathrm{mOsm} / \mathrm{kg}, \mathrm{pH}$ 7.2. Stimulation of axons was delivered through a patch-type pipette connected to either a Model A395 
linear stimulus isolator (World Precision Instruments) or a Model DS3 isolated current stimulator (Digitimer).

Schaffer collateral responses were recorded at the stratum radiatum of the $\mathrm{CA} 1$, with the stimulation electrode placed rostral to the recording electrode. Mossy fiber field EPSPs (fEPSPs) were recorded in the stratum lucidum of the hippocampus, whereas whole-cell recordings were performed by patching CA3 pyramidal cells. In both cases the MFs were stimulated at the border between the dentate gyrus and the hilus. At the end of each MF experiment, the group II metabotropic glutamate receptor agonist DCG-IV $(2 \mathrm{~S}, 20 \mathrm{R}, 30 \mathrm{R}-$ 2-[20,30-dicarboxycyclo-propyl] glycine) was applied to the bath (1 $\mu \mathrm{M}$ ) to selectively block MF responses (Kamiya et al., 1996). Recordings in which responses did not reduce by at least $80 \%$ were excluded from the analysis. For whole-cell recordings $100 \mu \mathrm{M}$ picrotoxin was added to the solution to avoid inhibitory transmission. For each sample, every recording was repeated at least three times and traces were averaged. Data was sampled at 20 or $50 \mathrm{kHz}$ and low-pass filtered at $2.9 \mathrm{kHz}$.

\section{Experimental Design and Statistical Analysis}

Electrophysiological data were analyzed using custom-written procedures in Igor Pro 6.3 (Wavemetrics). Statistical significance was tested using GraphPad Prism 7.04 (GraphPad Software). Two-way ANOVA tests were used to analyze high-frequency trains of stimulation. Extra sum-of-squares $F$ test was used to test differences between curve fits. This statistical method was chosen due to its robustness in comparing two nested models and returning a $p$-value in response to whether one curve adequately fits both data sets or whether two different curves better describe the data (Motulsky and Christopoulos, 2003). For all other tests two-tailed Student's unpaired $T$ test was used. For every experiment 3 or more animals were used. Results are reported as mean \pm SEM whereas " $n$ " refers to the number of slices recorded. Stimulation artifacts were digitally removed from electrophysiological traces for clarity.

\section{RESULTS}

To obtain a global knockout of Mover we bred Mover conditional knockout mice generated in the lab (Akula et al., 2019) with E2A-Cre mice. The E2A promoter drives Cre expression in the early mouse embryo, thus excising Mover in all cells from early embryonic stages on. The entire Mover gene consists of less than 4000 base pairs, including four exons and three introns (Figure 1A). We verified the expected excision of Mover exons 1, 2, and 3 by PCR (Figure 1B), and by sequencing the PCR product (Figure 1C). Western blotting revealed that Mover was not detected in hippocampal lysates from Mover knockout mice (Figure 1D). Likewise, there was no Mover immunofluorescence in sections of the hippocampus from Mover knockout mice (Figure 1E).

\section{Mover Knockout Affects Mossy Fiber but Not Schaffer Collateral Synaptic Transmission}

The absence of Mover in inhibitory synapses of the hippocampus (Wallrafen and Dresbach, 2018), together with its layered structure, makes it an ideal target to study the effect of Mover knockout in glutamatergic transmission. Recording of fEPSPs in the hippocampal CA1 with stimulation of the Schaffer collaterals (SC, Figure 2A) with increasing stimulation strength allows for an assessment of synaptic strength based on input-output curves. Input-output curves showed no difference in synaptic strength between WT and KO mice (Figure 2B).

To further probe changes in presynaptic transmission we evaluated short-term plasticity with three different protocols: paired-pulse facilitation with two pulses given at different interstimulus intervals (ISIs; Figure 2C), burst-induced facilitation with a $25 \mathrm{~Hz}$ train consisting of five stimuli (Figure 2D). In all protocols no differences between WT and KO were detected.

With no apparent differences in SC, we moved to investigate the CA3, more specifically the CA3 pyramidal cell inputs from MFs (Figure 3A). Mover was first observed to have high expression in the stratum lucidum, where MF form boutons with CA3 pyramidal cells (Kremer et al., 2007). However, we have recently shown that Mover is also strongly present in the stratum radiatum, where SC synapses are present (Wallrafen and Dresbach, 2018). MF boutons have very low release probability with particularly strong short-term plasticity effects (Nicoll and Schmitz, 2005) and would more easily reveal any possible changes in synaptic function in the absence of Mover.

Similarly to SC, input-output curves were unchanged by the absence of Mover (Figure 3B). However, a first assessment of the short-term plasticity parameters of $\mathrm{MF}$ KO already indicated a change in the absence of Mover: paired-pulse facilitation was slightly increased in KO synapses (Figure 3C), most pronouncedly at $40 \mathrm{~ms}$ ISI $(p=0.039$, Extra-sum-of-squares $F$ test).

These results were surprising considering that a previous report using whole-cell recordings found a reduced paired-pulse ratio in a knockdown of Mover at the calyx of Held (Körber et al., 2015). Therefore, to verify our finding we employed whole-cell patch clamp recordings from CA3 pyramidal cells. We initially characterized spontaneous activity onto the pyramidal cells in the presence of $1 \mu \mathrm{M}$ tetrodotoxin (TTX) and $100 \mu \mathrm{M}$ of the GABA receptor blocker picrotoxin, so that recordings comprised of only miniature EPSCs. Amplitude and frequency of miniature EPSCs were unchanged in the KO (Figures 4A-D). The kinetics of transmission, namely rise time and decay, were also comparable between WT and KO (Figures 4E,F).

With absence of changes in spontaneous synaptic activity in the CA3 pyramidal cells we set out to verify the change in facilitation observed in extracellular recordings using intracellular recordings. These recordings were also done in the presence of $100 \mu \mathrm{M}$ picrotoxin to abolish possible biases introduced by inhibitory transmission. Because the CA3 is a highly auto-associative area (Hablitz, 1984; Traub et al., 1993) we took extra precautions to prevent polysynaptic inputs 


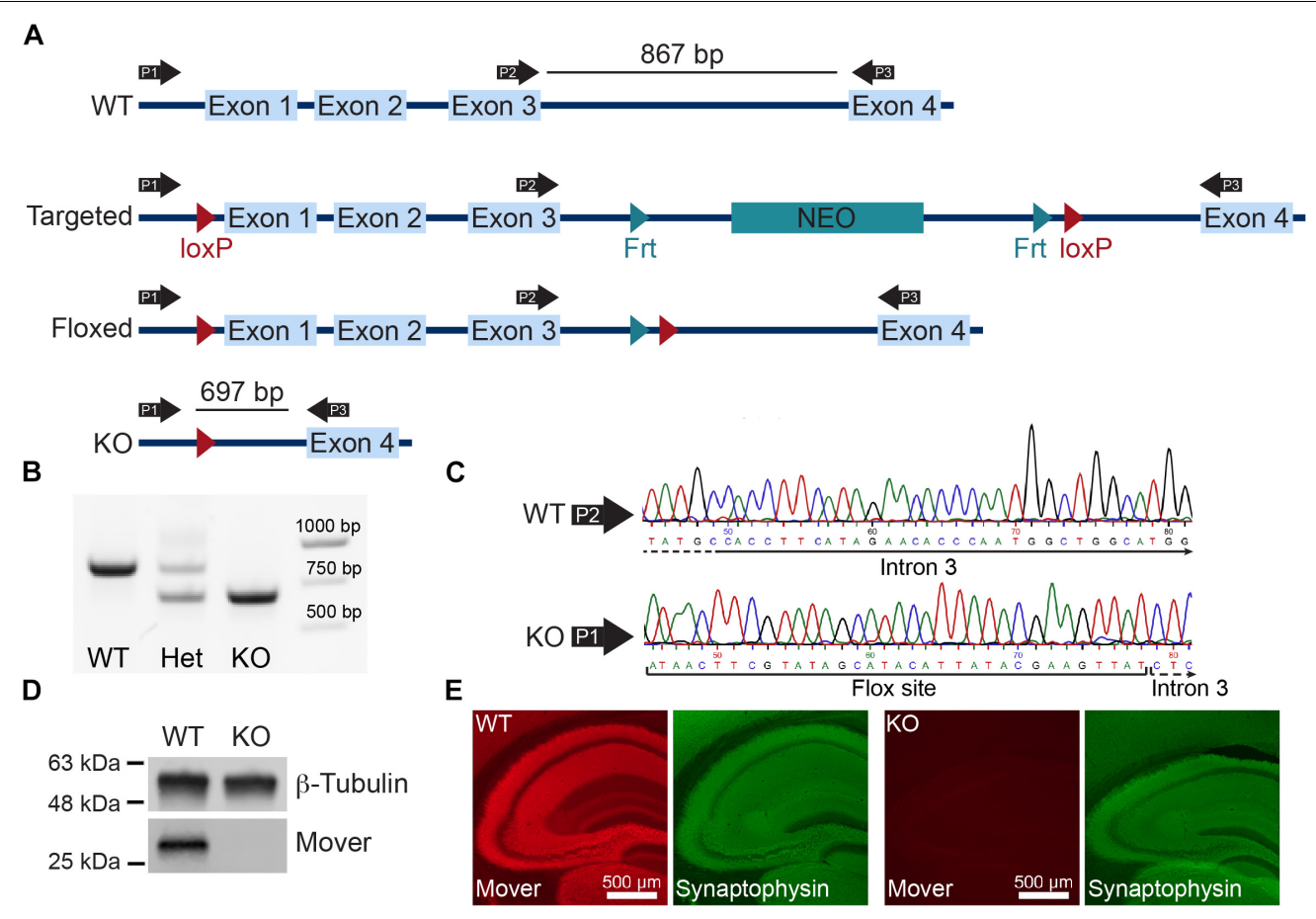

FIGURE 1 | Global knockout of Mover. (A) Gene targeting strategy for Mover KO mice. (B) Results of the PCR used for genotyping. Primers P1, P2, and P3 shown in panel (A) were always used in the same reaction. When a WT and a KO allele were present, P1 and P3 produce a 697 bp band, P2 and P3 produce a 867 bp band (lane "Het"). When only WT alleles are present the primers produce only the 867 bp band (lane "WT"), when only KO alleles are present the primers produce only the 697 (lane "KO"). (C) Example of sequencing results for WT (top) and KO (bottom). Examples shown start from nucleotide 45 from sequencing result and show a part of intron 3 using the primer P2 for WT and the flox site followed by intron 3 in KO, showing the absence of exons 1-3. (D) Western blot of lysates from dissected hippocampi from WT (left) and KO mice (right) probed for $\beta$-Tubulin and Mover. (E) Immunofluorescence of WT (left) and KO (right) mouse brain sections stained for Mover and Synaptophysin.

by blocking $\alpha$-amino-3-5-methyl-4-isoxazolepropionic acid (AMPA) receptors with $10 \mu \mathrm{M}$ of 2,3-dihydroxy-6-nitro-7sulfamoylbenzo[f]quinoxaline-2,3-dione (NBQX). Therefore, the responses comprised of $N$-methyl-D-aspartate receptor EPSCs (NMDA-EPSCs).

The amplitude of single evoked NMDA-EPSCs did not vary between $\mathrm{WT}$ and $\mathrm{KO}$ (Figure 5A). Confirming the previous observation in extracellular recordings and adding to it, paired-pulse facilitation was increased across all ISIs tested (Figure 5B, $p=0.016$, Extra-sum-of-squares $F$ test). This confirmed the change in short-term plasticity observed with extracellular recordings.

\section{Mover Strongly Affects Release Upon Repetitive Stimulation}

One of the hallmarks of MF is the ability to strongly facilitate, not only during a paired-pulse protocol, but also during repetitive stimulation under a vast range of frequencies (Nicoll and Schmitz, 2005). We therefore proceeded to analyze the effect of Mover deletion on responses upon repetitive stimulation, which could make the effects of the deletion even more prominent.

Trains of five stimuli at $25 \mathrm{~Hz}$ with extracellular recordings elicited a strong facilitation in both WT and KO MF. However,
KO MF had even stronger facilitation than WT ( $p=0.0004$, twoway ANOVA), reaching more than a 10 -fold increase in fEPSP amplitude (Figure 6A).

An increase in synaptic transmission in response to increasing stimulation frequencies, even at low frequencies, is a hallmark of MF facilitation, often referred as frequency facilitation (Nicoll and Schmitz, 2005). Using low-frequency stimulation led to similar enhanced facilitation of $\mathrm{KO}$ responses: change from frequency of stimulation from 0.05 to $0.2 \mathrm{~Hz}$ led to $\mathrm{KO}$ responses 30\% stronger than WT (Figure 6B, $p=0.0007$ ). Further increasing the frequency of stimulation to $0.5 \mathrm{~Hz}$ led to $\mathrm{KO}$ responses to facilitate $40 \%$ more than WT $(p<0.0001)$.

Furthermore, we probed the paired-pulse facilitation elicited by stimulation of an ISI of $40 \mathrm{~ms}$, repeated with a waiting time of either $20 \mathrm{~s}(0.05 \mathrm{~Hz}), 5 \mathrm{~s}(0.2 \mathrm{~Hz})$, or $2 \mathrm{~s}$ $(0.5 \mathrm{~Hz})$, i.e., the frequencies described in the previous experiment. Because both frequency facilitation and paired-pulse ratio depend on the residual calcium inside the presynaptic terminal we expected that the two would interact negatively, i.e., as frequency facilitation rises, paired-pulse ratio would decrease; and Mover should still affect paired-pulse ratio. Indeed, as expected, paired-pulse ratios were smaller at higher frequencies and the absence of Mover increase pairedpulse ratio on frequencies 0.05 (Figure 6C, $p=0.042$ ) and $0.2 \mathrm{~Hz}(p=0.046)$. 


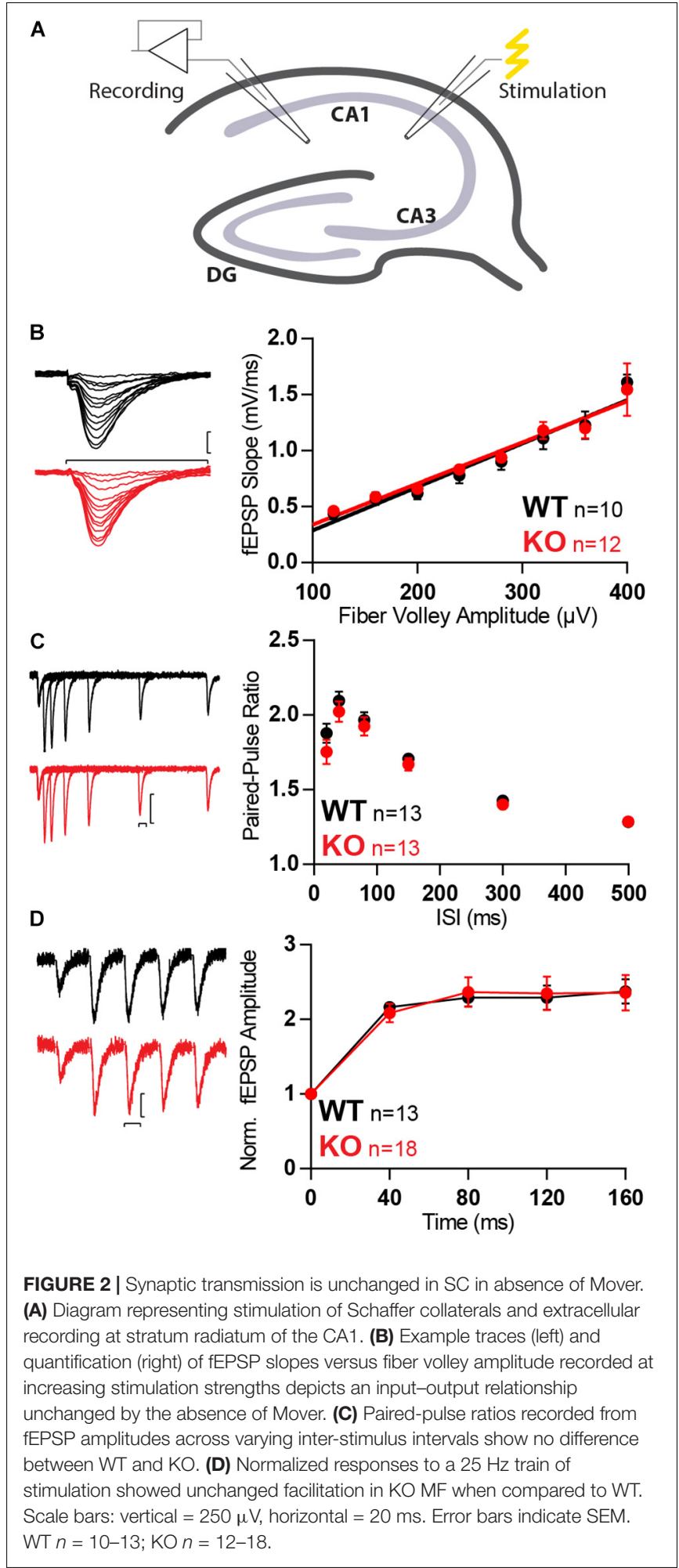

Because of this recent evidence of its influence on $\mathrm{MF}$ short-term facilitation and previous evidence of its influence in calcium-sensitivity of release (Körber et al., 2015), we decided to investigate whether there is a calcium-dependency of Mover effects on synaptic release. And since residual calcium is changed
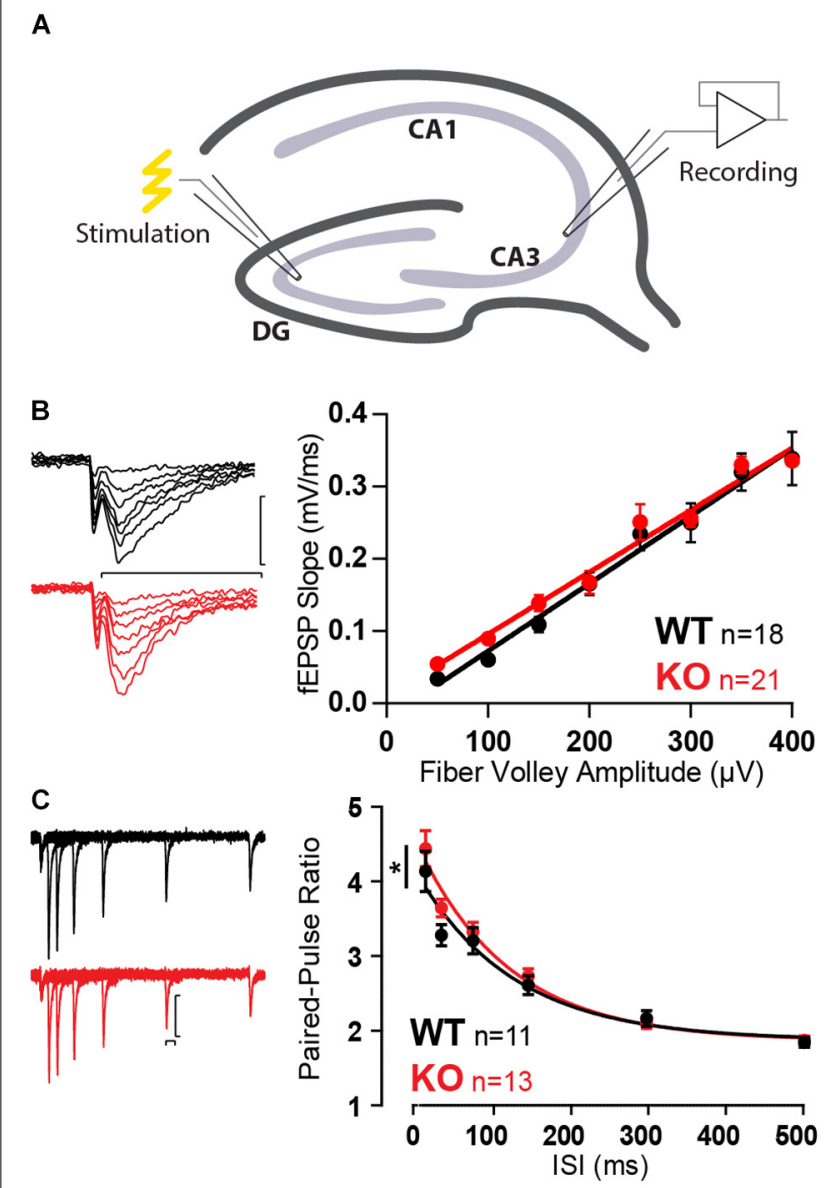

FIGURE 3 | Increased paired-pulse ratio in MF in absence of Mover. (A) Diagram representing stimulation of mossy fibers and extracellular recording in the stratum lucidum of the CA3. (B) Example traces (left) and quantification (right) of fEPSP slopes versus fiber volley amplitude recorded at increasing stimulation strengths depicts an input-output relationship unchanged by the absence of Mover. (C) Paired-pulse ratios recorded from fEPSP amplitudes across varying inter-stimulus intervals reveal increased facilitation in $\mathrm{KO}$ when compared to WT. Scale bars: vertical $=250 \mu \mathrm{V}$, horizontal $=20 \mathrm{~ms}$. Error bars indicate SEM. MF WT $n=11-18 ; \mathrm{KO} n=13-22 .{ }^{*} p<0.05$.

in MF with age (Mori-Kawakami et al., 2003) we decided to investigate the effect of the $\mathrm{KO}$ in older animals.

\section{Mover Affects MF Facilitation Under High Calcium Conditions}

The extent of facilitation in MF is known to reduce with age (Mori-Kawakami et al., 2003). Hence, to further explore the effect of the absence of Mover we analyzed the effect of MF stimulation in older mice (8-week old) with different extracellular calcium concentrations. The change in calcium concentration was compensated with magnesium, to keep the concentration of divalent ions constant.

Firstly, increasing the concentration of calcium from 1.25 to $2.5 \mathrm{mM}$ and further to $3.5 \mathrm{mM}$ led to an increase in fEPSP amplitude. This increase was similar when comparing WT and KO responses (Figure 7A). 
A
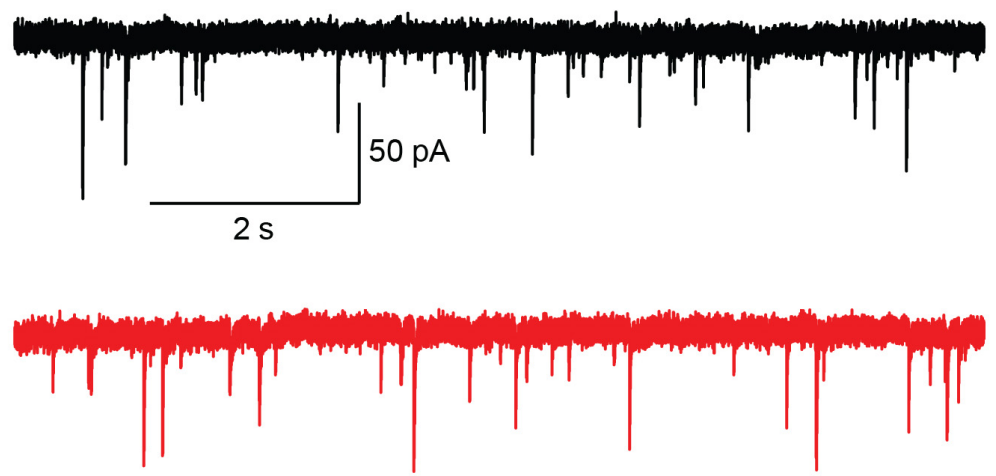

B

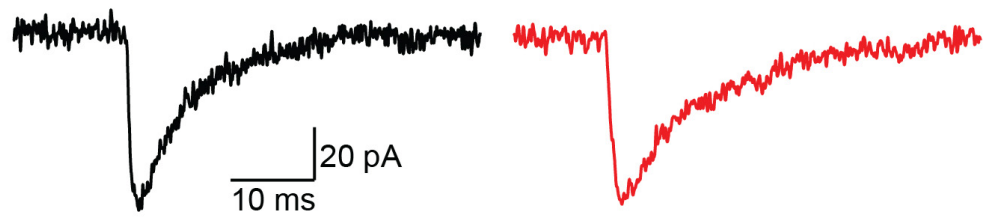

$\mathbf{C}_{1}$

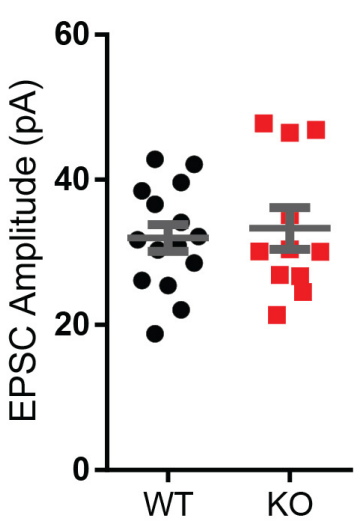

D

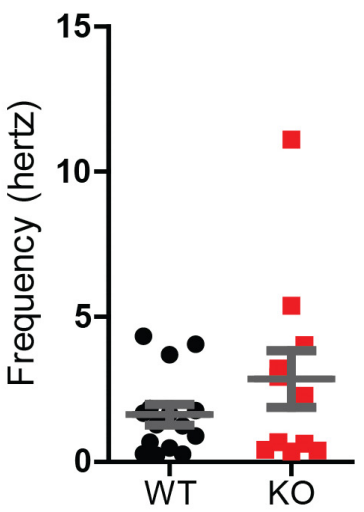

$\mathrm{C}_{2}$

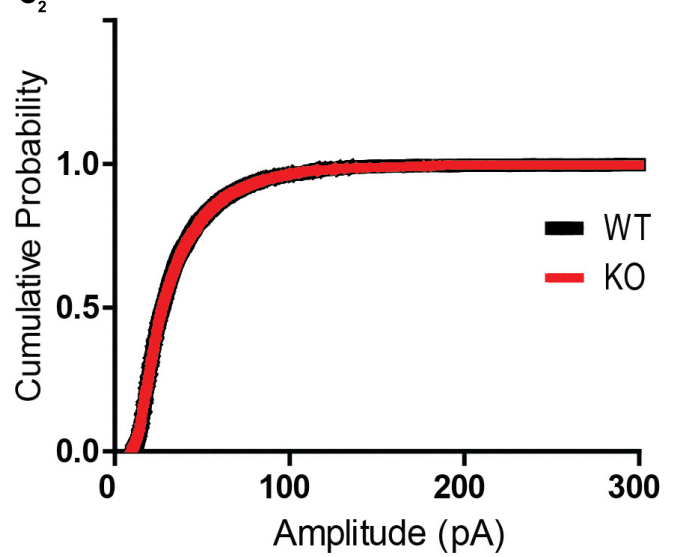

E

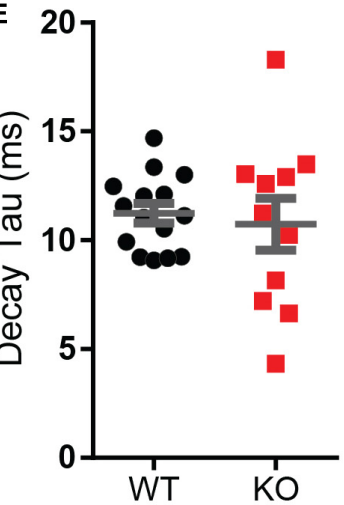

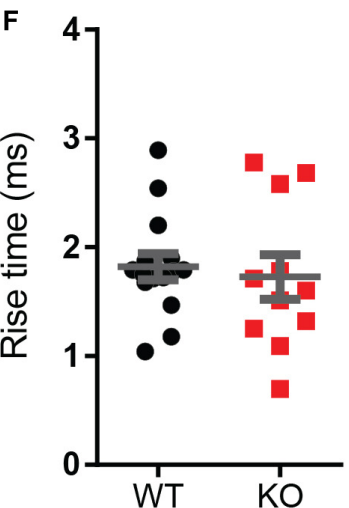

FIGURE 4 | Absence of Mover does not interfere with miniature EPSC parameters in CA3 pyramidal cells. (A) Representative traces from WT (gray) and KO (red) CA3 pyramidal cells under presence of $1 \mu \mathrm{M}$ TTX. (B) Representative miniature EPSC waveform from traces in A. (C) Amplitudes of miniature EPSC events were unchanged in their average amplitude $\left(\mathbf{C}_{\mathbf{1}}\right)$ and in their cumulative probability $\left(\mathbf{C}_{\mathbf{2}} \mathbf{)}\right.$. (D) Frequency of events was not changed by the absence of Mover. Miniature EPSC kinetics, namely the time constant of decay $\mathbf{( E )}$ and the 10-90 rise time (F), showed no difference between WT and KO. Error bars indicate SEM. WT $n=15$; $\mathrm{KO} n=11$.

When testing the previously used short-term plasticity protocols, at $1.25 \mathrm{mM} \mathrm{Ca}^{2+}$ the extent of facilitation did not differ between WT and KO anymore (Figure 7B). Surprisingly, after increasing $\mathrm{Ca}^{2+}$ to $2.5 \mathrm{mM}$, WT and $\mathrm{KO}$ continued to facilitate to the same extent (Figure $7 \mathrm{C}$ ), whereas the same calcium concentration in 3 week-old animals promoted a stronger 


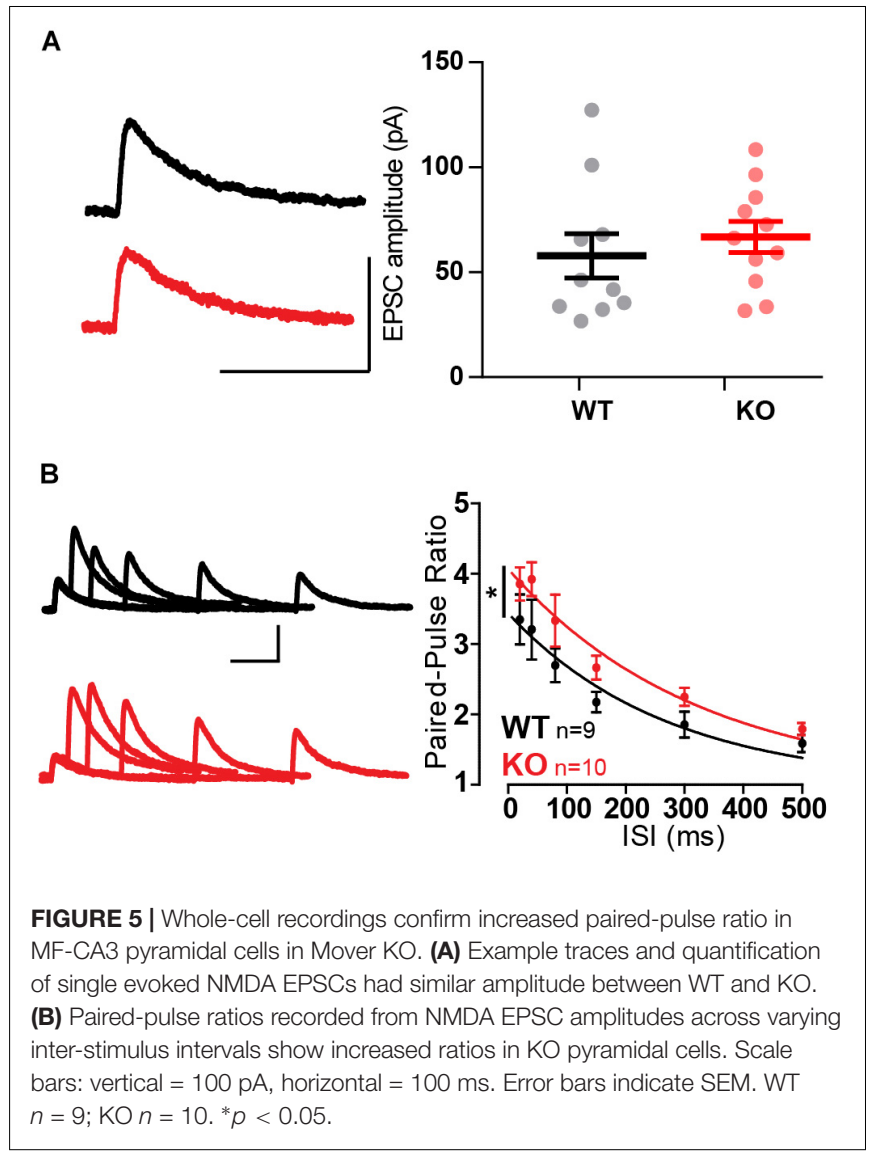

facilitation in MF KOs (Figures 6A,B). This reveals an agedependency of the effect that Mover has on facilitation.

When further increasing $\mathrm{Ca}^{2+}$ concentration to $3.5 \mathrm{mM}$, the difference in the extent of facilitation between $\mathrm{KO}$ and WT becomes obvious again for both high-frequency (Figure $\mathbf{7 D}_{2}$; $p=0.04$ ) and low-frequency facilitation (Figure $7 \mathbf{D}_{1} ; 0.05 \mathrm{~Hz}$ vs. $0.2 \mathrm{~Hz}: p=0.04 ; 0.05 \mathrm{~Hz}$ vs. $0.5 \mathrm{~Hz}: p=0.03$ ). The $\mathrm{KO}$ responses facilitate more than WT, corroborating what was observed in younger animals and the idea that Mover acts in a calciumdependent manner.

\section{Forskolin Occludes the Boost in Facilitation Observed in KO}

Synaptic plasticity in MF is known to be strongly tied to intracellular levels of cAMP and is, therefore, subject to regulation by forskolin (Weisskopf et al., 1994). Hence, since both forskolin and Mover strongly affect plasticity in MF we decided to investigate if Mover acts in the cAMP pathway.

We anticipated that, if Mover participates in this pathway and is involved in the potentiation caused by forskolin, we would observe changes in the degree of potentiation between WT and KO. However, application of forskolin led to a similar potentiation of WT and KO fEPSPs, suggesting that Mover is not necessary forskolin-driven potentiation. On the other hand, after forskolin potentiation we observed a lack of difference between WT and KO low- and high-frequency facilitation (Figures 8A,B).
This lack of a $\mathrm{KO}$ effect in facilitation after forskolin potentiation contrasts with the increased facilitation we observed in the absence of forskolin (Figures 6A,B, also in Figure 8B for comparison). Therefore, potentiation by forskolin occluded the increase in facilitation observed in the KO. These results suggest that Mover interacts with the cAMP pathway in MF, dampening facilitation in situations of high activity.

\section{DISCUSSION}

Mover is a synaptic vesicle protein with a remarkably heterogenous expression pattern in the rodent brain (Wallrafen and Dresbach, 2018). In addition, C. elegans and Drosophila lack Mover related genes. Thus, Mover is not essential for synaptic transmission. Instead, it may modulate neurotransmitter release at certain synapses, contributing to synaptic heterogeneity. To test whether Mover has a role in transmitter release we analyzed a mouse-line lacking Mover. We found that the knockout of Mover affects short-term synaptic plasticity in the hippocampal MFs but not in the downstream synapses, i.e., SC. Pairedpulse ratio and responses to train of stimulation led to stronger facilitation in MF terminals in the absence of Mover. In particular, frequency facilitation, a hallmark of presynaptic plasticity at MF terminals (Nicoll and Schmitz, 2005), was strongly increased in Mover knockout mice. This increased facilitation was stronger in younger animals and in situations of high calcium concentration, and was occluded by increasing cAMP levels.

\section{Mover Has Synapse-Specific Effects on Neurotransmitter Release}

The increase in paired-pulse facilitation in KO MF can be explained by a reduction in synaptic vesicle release probability, because of the inverse relationship between the two (Zucker and Regehr, 2002). The change in MF contrasts with the absence of changes in release in KO SC. Curiously, despite the lack of the effect of the $\mathrm{KO}$ in SC, Mover concentration in WT mice is known to be higher in the area of SC synapses than that of MF synapses (Wallrafen and Dresbach, 2018), so the effect of Mover on synaptic release does not seem to scale with its concentration. To add to the heterogeneity of Mover function, a study in the calyx of Held described an increase in release probability in a knockdown of Mover in the calyx of Held (Körber et al., 2015). The contrasting results between the calyx of Held and MF could arise from the different approach (knockdown vs. knockout) or from the different species (rat vs. mouse). However, when seen in combination with the lack of changes in SC, a hypothesis arises: Mover has synapse-specific effects. The synapse-specific way in which Mover seems to regulate transmission could add heterogeneity to the ubiquitous functions of the transmitter release machinery. In addition, we speculate that at certain synapses, i.e., at MF and the calyx of Held, the differential action of Mover could have a common effect in constraining synaptic strength. MF transmission relies heavily on facilitation for efficient information transfer and is, therefore, considered a "conditional detonator" (Vyleta et al., 2016). We have shown that Mover constrains facilitation in this synapse, 

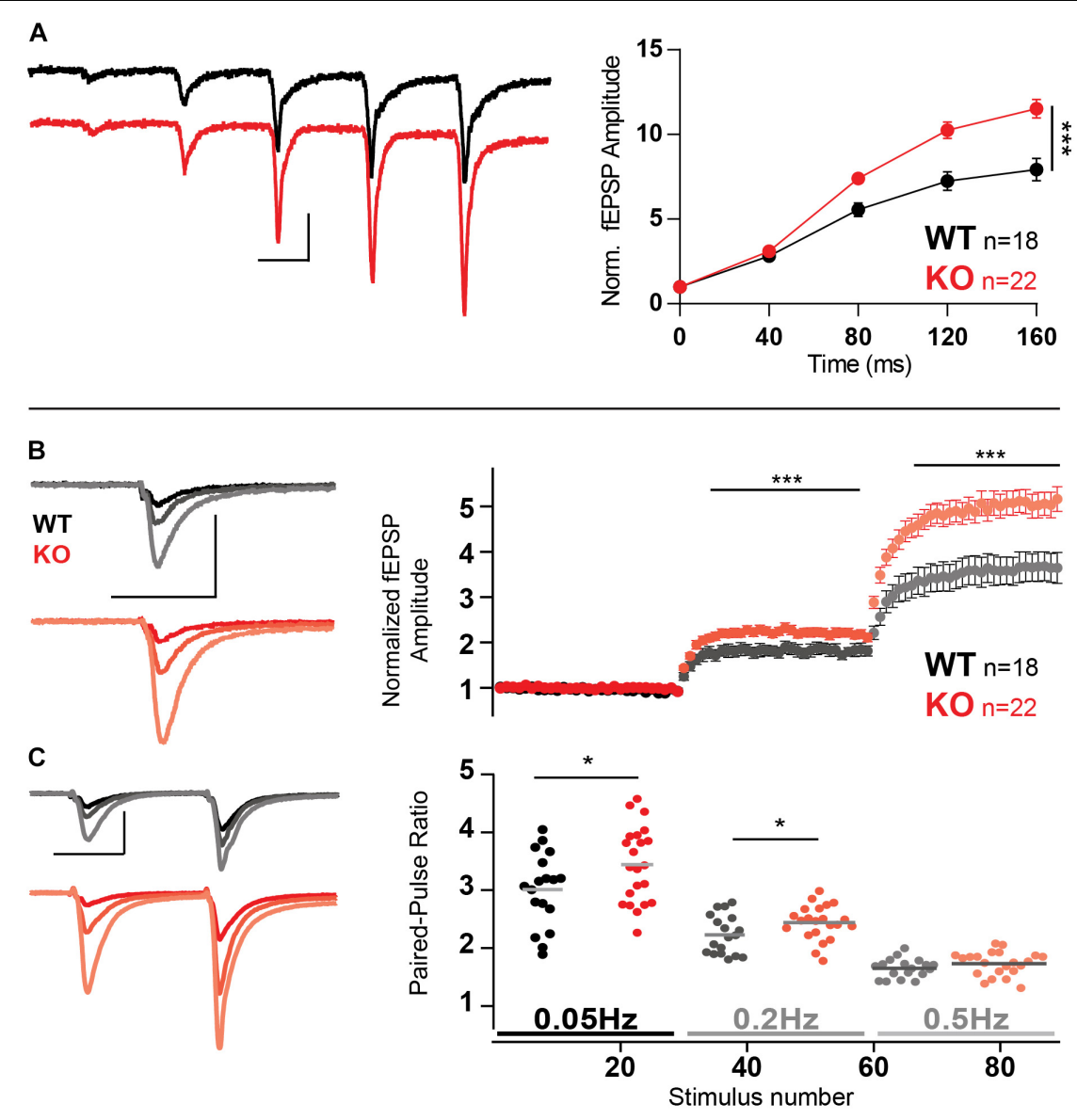

FIGURE 6 | Increased facilitation in MF in the absence of Mover. (A) Example traces and normalized responses to $25 \mathrm{~Hz}$ trains of stimulation showed increased facilitation in KO MF when compared to WT. (B) Normalized responses to stimuli delivered at 0.05, 0.2, and $0.5 \mathrm{~Hz}$ reveal increased facilitation in KO MF. Responses were normalized to the amplitude of the first fEPSP. (C) Paired-pulse ratio with an inter-stimulus interval of $40 \mathrm{~ms}$ using the same stimulation frequencies as above (0.05, 0.2, and $0.5 \mathrm{~Hz}$, see text). Scale bars: vertical = $500 \mu \mathrm{V}$, horizontal = $20 \mathrm{~ms}$. Error bars indicate SEM. SC WT $n=10-13$; SC KO $n=12-18$; MF WT $n=18$; $\mathrm{KO} n=22 .{ }^{*} p<0.05 ;{ }^{* * *} p<0.001$.

possibly keeping detonation within physiological range. On the other hand, Mover reduces the amplitude of the first response to a train of stimuli and subsequent depression in a synapse where this initial response is vital for transmission of fast and reliable auditory information, the calyx of Held (Englitz et al., 2009; Körber et al., 2015). Thus, in general, Mover could have the potential to act as a buffer for synaptic strength. Further experiments to test this in different synapses and to elucidate the mechanism of action of Mover could help prove or disprove such a hypothesis.

Such a differential effect on synaptic release in different synapses is not exclusive to Mover. For example, a similar synapse-specific effect on hippocampal synaptic transmission and plasticity was previously observed with the priming protein Munc13-2, where deletion of this protein led to increased facilitation and lower release probability in MF but not in SC (Breustedt et al., 2010). In the case of Munc13-2, the mechanism through which it affects neurotransmitter release is more straightforward since the Munc13 proteins are known to be vesicle priming factors (Augustin et al., 1999; Varoqueaux et al., 2002).
Alternatively, Mover may affect facilitation directly - with or without affecting release probability - in a similar way like the calcium sensor protein Synaptotagmin 7 (Jackman et al., 2016). In this case, however, Mover would be acting as an inhibitor of facilitation, i.e., in the opposite direction compared to Synaptotagmin 7, which increases facilitation. In any case, Mover seems to be under the influence of $\mathrm{Ca}^{2+}$, as discussed below (see section " $\mathrm{Ca}^{2+}$ Dependency of Mover Action").

\section{Calcium Dependency of MF Plasticity: Technical Considerations}

Synaptic facilitation is largely dependent on free or bound residual $\mathrm{Ca}^{2+}$ in the presynaptic terminal (Zucker and Regehr, 2002; Jackman and Regehr, 2017). One exception to this is the activity-dependent release of polyamine blocks in AMPA receptors (Rozov and Burnashev, 1999), but it is not present in MF to CA3 pyramidal synapses (Toth et al., 2000). Facilitation at MF-CA3 synapse is closely correlated with the concentration of $\mathrm{Ca}^{2+}$ in the presynaptic terminal (Regehr et al., 1994) and 

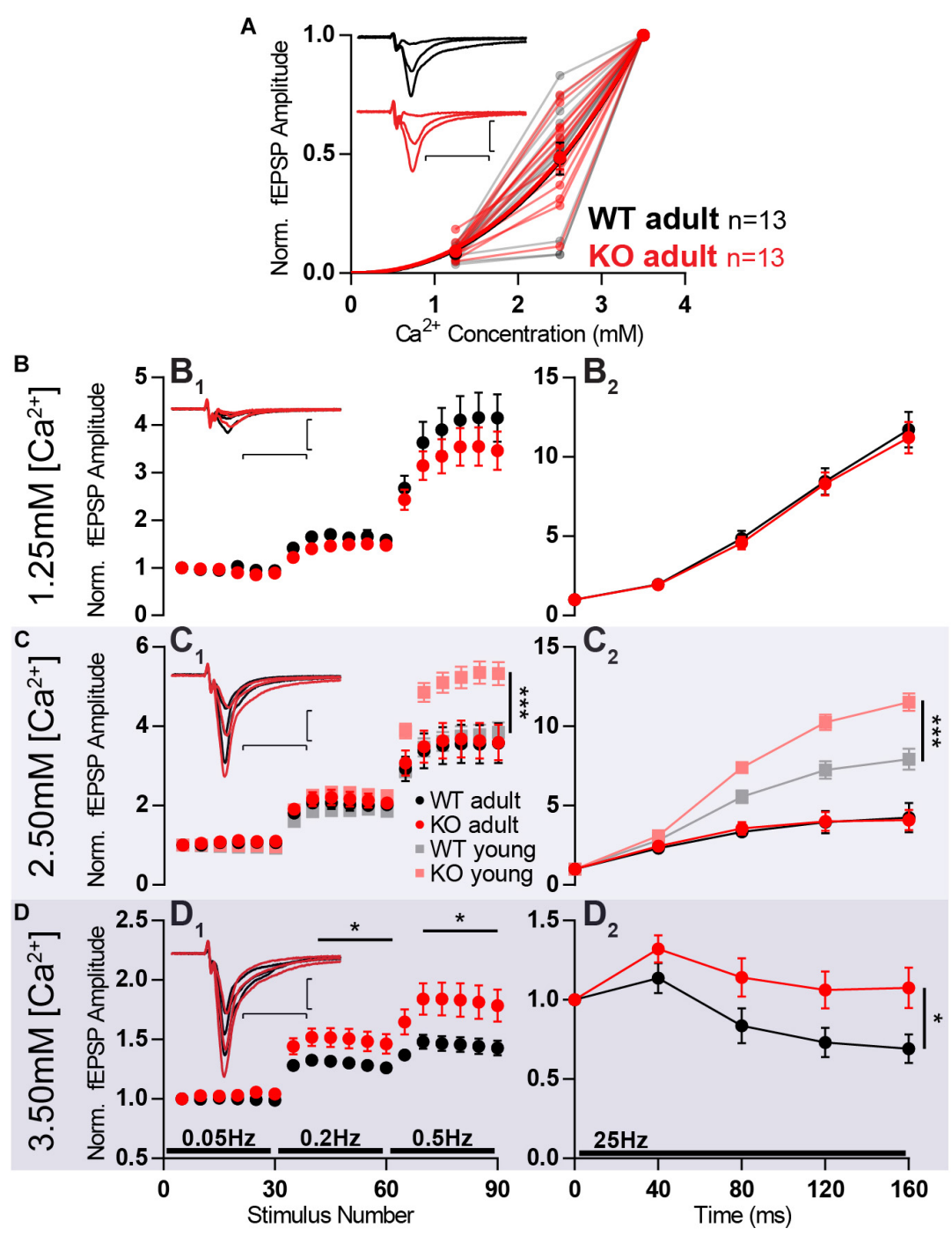

FIGURE 7 | Increased facilitation in KO is age- and calcium-dependent. MF of 8-week old animals $\mathrm{KO}$ (KO adult) has stronger facilitation than WT (WT adult) only in high extracellular calcium concentration. (A) Increasing calcium concentration leads to similar baseline responses in WT and KO. Responses were normalized to

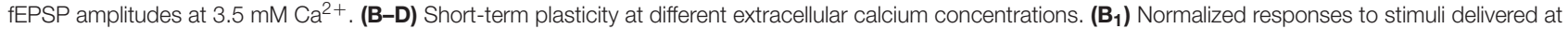
$0.05,0.2$, and $0.5 \mathrm{~Hz}$ at $1.25 \mathrm{mM}$ extracellular calcium. $\left(\mathbf{B}_{\mathbf{2}}\right)$ Normalized responses to a $25 \mathrm{~Hz}$ train of stimulation at $1.25 \mathrm{mM}$ extracellular calcium. $\left(\mathbf{C}_{\mathbf{1}}\right)$ Normalized responses to stimuli delivered at $0.05,0.2$, and $0.5 \mathrm{~Hz}$ at $2.5 \mathrm{mM}$ extracellular calcium, in four different conditions: 8-week old WT (adult), 8-week old KO (adult),

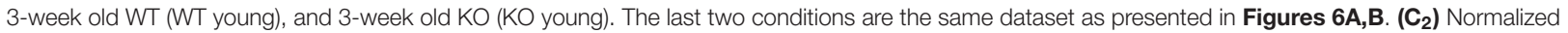
responses to a $25 \mathrm{~Hz}$ train of stimulation at $2.5 \mathrm{mM}$ extracellular calcium. $\left(\mathbf{D}_{\mathbf{1}}\right)$ Normalized responses to stimuli delivered at $0.05,0.2$, and $0.5 \mathrm{~Hz}$ at $3.5 \mathrm{mM}$ extracellular calcium. $\left(\mathbf{D}_{\mathbf{2}}\right)$ Normalized responses to a $25 \mathrm{~Hz}$ train of stimulation at $3.5 \mathrm{mM}$ extracellular calcium. $\left(\mathbf{B}_{1}, \mathbf{C}_{1}, \mathbf{D}_{1}\right)$ Each dot represents the average response to five consecutive stimuli. (B-D) Responses were normalized to the amplitude of the first fEPSP. (Insets) Representative traces from WT (black) and KO (red) hippocampi. Scale bars: vertical $=1 \mathrm{mV}$, horizontal $=10 \mathrm{~ms}$. Error bars indicate SEM. WT adult $n=13 ; \mathrm{KO}$ adult $n=13 .{ }^{*} p<0.05 ;{ }^{* * *} p<0.001$.

happens over a wide range of frequencies (Salin et al., 1996), which we also observed in our experiments.

Different mechanisms have been proposed to explain the relationship between $\mathrm{Ca}^{2+}$ and facilitation at this synapse. First, the presence of calcium buffers coupled with a loose coupling between $\mathrm{Ca}^{2+}$ channels and $\mathrm{Ca}^{2+}$ sensors (Blatow et al., 2003; Vyleta and Jonas, 2014) could act in a way that repeated stimulation could saturate the buffers and allow for a stronger presence of available $\mathrm{Ca}^{2+}$ to act on the release sensor. Another proposed mechanism is the presence of a second
$\mathrm{Ca}^{2+}$ sensor, a "facilitation sensor," with high affinity and slow kinetics, which would remain bound to calcium after the action potential-evoked calcium transient. In Jackman et al. (2016) proposed that this sensor is Synaptotagmin 7 as the $\mathrm{KO}$ of Synaptotagmin 7 shows a dramatic reduction on the degree of MF facilitation. Other mechanisms that could underlie facilitation at MF-CA3 synapse include distinct contribution from different $\mathrm{Ca}^{2+}$ channel types (Chamberland et al., 2017), modulation by adenosine receptors (Moore et al., 2003; Gundlfinger et al., 2007a; Klausnitzer and Manahan-Vaughan, 2008), by Kainate 
A

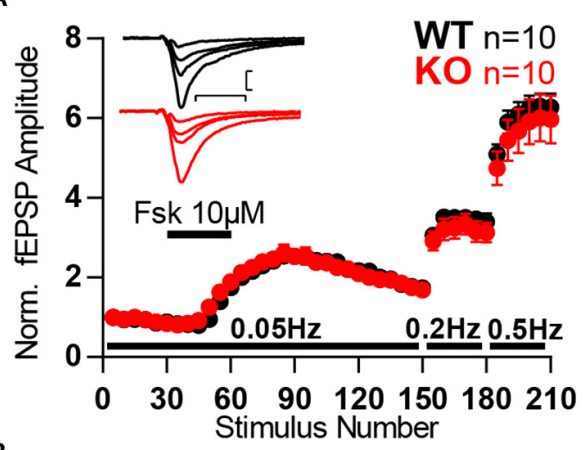

B

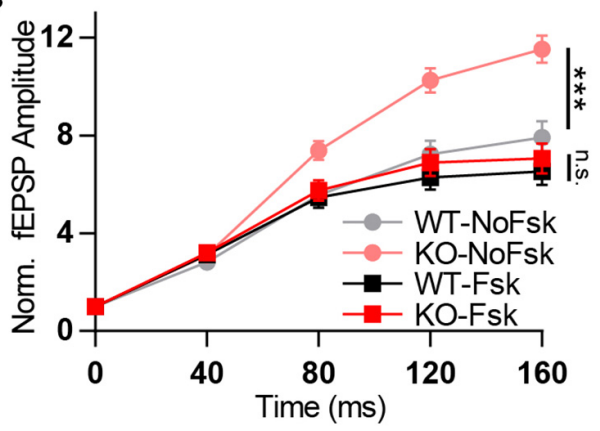

FIGURE 8 | Forskolin potentiation occlude KO boost in facilitation.

(A) Normalized MF fEPSP amplitudes during the time course of experiment in which forskolin (fsk, $10 \mu \mathrm{M}$ ) is applied for $10 \mathrm{~min}$ and frequency of stimulation is changed from 0.05 to 0.2 and further to $0.5 \mathrm{~Hz}$. Each data point corresponds to the average response to five consecutive stimuli. (Inset) Representative traces from WT (black) and KO (red) hippocampi.

(B) Normalized MF responses to a $25 \mathrm{~Hz}$ train of stimulation in four different conditions: WT without forskolin application (WT-NoFsk), KO without forskolin application (KO-NoFsk), WT after forskolin potentiation (WT-Fsk), and KO after forskolin potentiation (KO-Fsk). The first two conditions are the same dataset as present in Figure 6B. Responses were normalized to the amplitude of the first response. Scale bars: vertical $=200 \mu \mathrm{V}$, horizontal $=10 \mathrm{~ms} ; \mathrm{WT} n=10$; $\mathrm{KO} n=10$. Error bars indicate SEM. n.s.: not significant; ${ }^{* * *} p<0.001$.

receptors (Lauri et al., 2001; Schmitz et al., 2001; Breustedt and Schmitz, 2004) often in connection with increased $\mathrm{Ca}^{2+}$ influx or $\mathrm{Ca}^{2+}$ release from internal stores (Kamiya et al., 2002; Lauri et al., 2003; Scott and Rusakov, 2006; Scott et al., 2008) and the CaM and/or adenylyl cyclase pathways (Salin et al., 1996; Wang et al., 2003; Rodríguez-Moreno and Sihra, 2004; Andrade-Talavera et al., 2012).

The mechanisms that affect facilitation in response to highfrequency stimulation and low-frequency stimulation (frequency facilitation) greatly overlap. It has been previously described that both phenomena act on residual calcium and occlude each other (Salin et al., 1996). As in Salin et al. (1996), our work shows that increase of frequency facilitation led to a reduction in paired-pulse facilitation (Figure 6), suggesting that both processes operate under a common mechanism. Admittedly, due to the long-lasting nature of frequency facilitation, and different modulation between the two time ranges (Gundlfinger et al., $2007 b$ ), the involvement of intermediary biochemical processes that are independent of residual $\mathrm{Ca}^{2+}$ have been suggested (Nicoll and Schmitz, 2005; Sihra and Rodríguez-Moreno, 2013) possibly by acting in the CaM and cAMP pathways (Salin et al., 1996; Wang et al., 2003; Rodríguez-Moreno and Sihra, 2004; Andrade-Talavera et al., 2012). Nevertheless, manipulations affecting frequency facilitation but not facilitation in the millisecond range still need to be performed to decisively show a mechanistic difference between the two different time scales.

In order to study how Mover is affecting facilitation and its calcium-dependency we have used different extracellular $\mathrm{Ca}^{2+}$ concentrations, which influence the $\mathrm{Ca}^{2+}$ influx into the synaptic terminal and changes release probability. The increase in $\mathrm{Ca}^{2+}$ was compensated by a decrease in extracellular $\mathrm{Mg}^{2+}$ in the opposite direction. This way, the concentration of divalent ions was kept constant. This minimizes the possible voltage shifts that could occur due to changes in surface charge screening. Nevertheless, we cannot rule out that shifts could have occurred since $\mathrm{Ca}^{2+}$ produces a stronger shift in surface potential than $\mathrm{Mg}^{2+}$ (Hille, 2001). Other mechanisms through which changing extracellular $\mathrm{Ca}^{2+}$ concentrations can lead to changes in excitability include its binding to voltagegated channels, blocking channel pores, through a G-protein coupled receptor called calcium-sensing receptor (CaSR) and through a calcium- and voltage-dependent cation channel called calcium homeostasis modulator 1 (Armstrong and Cota, 1990, 1991; Santarelli et al., 2007; Ma et al., 2012; Jones and Smith, 2016). In every case increased $\mathrm{Ca}^{2+}$ concentration leads to decreased excitability. On the other hand, the decrease of $\mathrm{Mg}^{2+}$ can also lead to consequences in neuronal transmission. Most notably, the reduction of $\mathrm{Mg}^{2+}$ concentration would lead to a reduced block on NMDA receptors (Nowak et al., 1984). The activation of NMDA receptors by glutamate in this situation would lead to stronger EPSCs with a slower decay. While the aforementioned effects may occur in our approach, we applied changes in $\mathrm{Ca}^{2+}$ and $\mathrm{Mg}^{2+}$ concentrations equally to both WT and KO samples. This way, even though excitability and synaptic responses would be altered when the $\mathrm{Ca}^{2+} / \mathrm{Mg}^{2+}$ ratio is changed they should be comparable between WT and KO and should not interfere with the analysis done here.

It is also important to note that CA3 pyramidal cells form an auto-associative network through associational recurrent axonal collaterals that target other CA3 pyramidal cells (Hablitz, 1984; Traub et al., 1993; Nicoll and Schmitz, 2005). Such organization can lead to the situation where the cell being recorded shows responses, not to a MF input, but from the synaptic release from another pyramidal cell, which was activated by the stimulation. Therefore, di- or poly-synaptic contamination, or even contamination from direct stimulation of association/commissural fibers is common in CA3 recordings. We took the following precautions to ensure monosynaptic MFCA3 pyramidal cell responses. Firstly, recordings were succeeded by application of DCG-IV, which selectively blocks MF responses (Kamiya et al., 1996). Therefore, recordings in which responses did not reduce by $80 \%$ were excluded from the analysis. Secondly, in whole-cell recordings NBQX was applied to the bath so that only NMDA receptor responses would occur. Because NMDA receptors are blocked by $\mathrm{Mg}^{2+}$ at resting potential polysynaptic responses are unlikely to occur (Weisskopf and Nicoll, 1995; Nicoll and Schmitz, 2005). Furthermore, the use of $4 \mathrm{mM} \mathrm{Ca}^{2+}$ 
and $\mathrm{Mg}^{2+}$ during whole-cell recordings further ensures pure monosynaptic responses due to three factors: increased block of NMDA receptors at resting membrane potential, reduced release probability and hyperpolarization of neurons due to surface charge screening (Nowak et al., 1984; Hille, 2001). Such strategies are commonly used (Salin et al., 1996; Kwon and Castillo, 2008a,b; Kaeser-Woo et al., 2013) to ensure absence of contamination in recordings and better quality of recordings.

\section{$\mathrm{Ca}^{2+}$ Dependency of Mover Action}

How does Mover interact with calcium signaling or the release machinery? The amino acid structure of Mover does not reveal any canonical calcium binding domain (Kremer et al., 2007). Here we observe an occlusion of the KO effect after activation of adenylyl cyclase by forskolin, which suggests that Mover and adenylyl cyclase - or its product, cAMP - act in the same pathway. Activation of adenylyl cyclase has been shown to increase neurotransmitter release in MF (Weisskopf et al., 1994; Tzounopoulos et al., 1998; Rodríguez-Moreno and Sihra, 2004). cAMP has been shown to influence release in MF through its direct targets Epac2 (exchange protein directly activated by cAMP) and protein kinase A (Weisskopf et al., 1994; RodríguezMoreno and Sihra, 2004). One proposed way through which synaptic activity increases cAMP levels is by the activation of adenylyl cyclases 1 and 8 by CaM (Villacres et al., 1998; Wang et al., 2003; Sihra and Rodríguez-Moreno, 2013). Mover could participate in this pathway via its known CaM binding property (Körber et al., 2015; Akula et al., 2019). Further experiments would be necessary to test this hypothesis.

The participation of Mover in a $\mathrm{Ca}^{2+}$-sensing pathway is corroborated by the observation that Mover affects MF plasticity differently under different extracellular calcium concentrations (Figure 7). This differential response indicates that there is a calcium-dependency of Mover action: it only influenced release in higher calcium concentrations.

The $\mathrm{Ca}^{2+}$-dynamics in MF also seem to change with age. The knockout of Mover also did not show an effect on short-term plasticity in older mice under the same experimental conditions as juvenile mice (Figure 7). When comparing 3- and 9-week old mice Mori-Kawakami et al. (2003) show reduced paired-pulse ratios and frequency-dependent facilitation in older mice. This was attributed to a lower availability of residual $\mathrm{Ca}^{2+}$. This lower $\mathrm{Ca}^{2+}$ concentration, in addition to the calcium-dependency of the effect of Mover explains the smaller effect of the $\mathrm{KO}$ in older

\section{REFERENCES}

Acuna, C., Liu, X., and Südhof, T. C. (2016). How to make an active zone: unexpected universal functional redundancy between RIMs and RIM-BPs. Neuron 91, 792-807. doi: 10.1016/j.neuron.2016.07.042

Ahmed, S., Wittenmayer, N., Kremer, T., Hoeber, J., Kiran Akula, A., Urlaub, H., et al. (2013). Mover is a homomeric phospho-protein present on synaptic vesicles. PLoS One 8:e63474. doi: 10.1371/journal.pone.0063474

Akula, A. K., Zhang, X., Viotti, J. S., Ebrecht, R., Reim, K., Wouters, F., et al. (2019). The Calmodulin binding region of the synaptic vesicle protein mover animals. It is also possible to assume that homeostatic plasticity could have played a stronger role in the older mice and, therefore, reduced the consequences of the absence of Mover. Nonetheless, the exact mechanism through which Mover acts to, most likely indirectly, sense intracellular $\mathrm{Ca}^{2+}$ levels and influence release will be the object of future studies.

\section{DATA AVAILABILITY STATEMENT}

The datasets generated for this study are available on request to the corresponding author.

\section{ETHICS STATEMENT}

The animal study was reviewed and approved by the Tierschutzkommission der Universitätsmedizin Göttingen.

\section{AUTHOR CONTRIBUTIONS}

JV performed the research, analyzed the data, designed the experiments, and wrote the manuscript. TD designed the experiments and wrote the manuscript.

\section{FUNDING}

This study was supported by the DFG Center for Nanoscale Microscopy and Molecular Physiology of the Brain (CNMPB, B1-1 to TD), as well as by the Excellence fellowship (DFG Grant GSC 226/1) provided by the Göttingen Graduate School for Neurosciences, Biophysics and Molecular Biosciences (GGNB to JV).

\section{ACKNOWLEDGMENTS}

We would like to thank Irmgard Weiß for expert technical assistance. We would also like to thank Thomas J. Younts and Yoav Ben-Simon for help with the electrophysiological recordings as well as Tobias Moser for kindly providing Cs-gluconate and many fruitful discussions. Some of the results presented here have been released as a Pre-Print at Viotti et al. (2019).

is required for homomeric interaction and presynaptic targeting. Front. Mol. Neurosci. 12:249. doi: 10.3389/fnmol.2019.00249

Andrade-Talavera, Y., Duque-Feria, P., Negrete-Díaz, J. V., Sihra, T. S., Flores, G., and Rodríguez-Moreno, A. (2012). Presynaptic kainate receptor-mediated facilitation of glutamate release involves Ca2+-calmodulin at mossy fiber-CA3 synapses. J. Neurochem. 122, 891-899. doi: 10.1111/j.1471-4159.2012.07844.x

Antonini, D., Dentice, M., Mahtani, P., De Rosa, L., Della Gatta, G., Mandinova, A., et al. (2008). Tprg, a gene predominantly expressed in skin, is a direct target of the transcription factor p63. J. Invest. Dermatol. 128, 1676-1685. doi: $10.1038 /$ jid.2008.12 
Armstrong, C. M., and Cota, G. (1990). Modification of sodium channel gating by lanthanum. Some effects that cannot be explained by surface charge theory. J. Gen. Physiol. 96, 1129-1140. doi: 10.1085/jgp.96.6.1129

Armstrong, C. M., and Cota, G. (1991). Calcium ion as a cofactor in Na channel gating. Proc. Natl. Acad. Sci. U.S.A. 88, 6528-6531. doi: 10.1073/pnas.88.15. 6528

Augustin, I., Rosenmund, C., Südhof, T. C., and Brose, N. (1999). Munc13-1 is essential for fusion competence of glutamatergic synaptic vesicles. Nature 400, 457-461. doi: 10.1038/22768

Blatow, M., Caputi, A., Burnashev, N., Monyer, H., and Rozov, A. (2003). $\mathrm{Ca} 2+$ buffer saturation underlies paired pulse facilitation in calbindinD28k-containing terminals. Neuron 38, 79-88. doi: 10.1016/s0896-6273(03)0 0196-x

Breustedt, J., Gundlfinger, A., Varoqueaux, F., Reim, K., Brose, N., and Schmitz, D. (2010). Munc13-2 differentially affects hippocampal synaptic transmission and plasticity. Cereb. Cortex 20, 1109-1120. doi: 10.1093/cercor/bhp170

Breustedt, J., and Schmitz, D. (2004). Assessing the role of GLUK5 and GLUK6 at hippocampal mossy fiber synapses. J. Neurosci. 24, 10093-10098. doi: 10.1523/ jneurosci.3078-04.2004

Bruckner, J. J., Gratz, S. J., Slind, J. K., Geske, R. R., Cummings, A. M., Galindo, S. E., et al. (2012). Fife, a drosophila Piccolo-RIM homolog, promotes active zone organization and neurotransmitter release. J. Neurosci. 32, 17048-17058. doi: 10.1523/JNEUROSCI.3267-12.2012

Burré, J., Beckhaus, T., Corvey, C., Karas, M., Zimmermann, H., and Volknandt, W. (2006). Synaptic vesicle proteins under conditions of rest and activation: analysis by 2-D difference gel electrophoresis. Electrophoresis 27, 3488-3496. doi: 10.1002/elps.200500864

Butola, T., Wichmann, C., and Moser, T. (2017). Piccolo promotes vesicle replenishment at a fast central auditory synapse. Front. Synaptic Neurosci. 9:14. doi: 10.3389/fnsyn.2017.00014

Cases-Langhoff, C., Voss, B., Garner, A., Appeltauer, U., Takei, K., Kindler, S., et al. (1996). Piccolo, a novel $420 \mathrm{kDa}$ protein associated with the presynaptic cytomatrix. Eur. J. Cell Biol. 69, 214-223.

Chamberland, S., Evstratova, A., and Tóth, K. (2017). Short-term facilitation at a detonator synapse requires the distinct contribution of multiple types of voltage-gated calcium channels. J. Neurosci. 37, 792-807. doi: 10.1523/ JNEUROSCI.0159-17.2017

Englitz, B., Tolnai, S., Typlt, M., Jost, J., and Rübsamen, R. (2009). Reliability of synaptic transmission at the synapses of held in vivo under acoustic stimulation. PLoS One 4:e7014. doi: 10.1371/journal.pone.0007014

Fejtova, A., and Gundelfinger, E. D. (2006). Molecular organization and assembly of the presynaptic active zone of neurotransmitter release. Results Probl. Cell Differ. 43, 49-68. doi: 10.1007/400_012

Gundelfinger, E. D., Reissner, C., and Garner, C. C. (2016). Role of bassoon and piccolo in assembly and molecular organization of the active zone. Front. Synaptic Neurosci. 7:19. doi: 10.3389/fnsyn.2015.00019

Gundlfinger, A., Bischofberger, J., Johenning, F. W., Torvinen, M., Schmitz, D., and Breustedt, J. (2007a). Adenosine modulates transmission at the hippocampal mossy fibre synapse via direct inhibition of presynaptic calcium channels. J. Physiol. 582, 263-277. doi: 10.1113/jphysiol.2007.132613

Gundlfinger, A., Leibold, C., Gebert, K., Moisel, M., Schmitz, D., and Kempter, R. (2007b). Differential modulation of short-term synaptic dynamics by longterm potentiation at mouse hippocampal mossy fibre synapses. J. Physiol. 585, 853-865. doi: 10.1113/jphysiol.2007.143925

Hablitz, J. J. (1984). Picrotoxin-induced epileptiform activity in hippocampus: role of endogenous versus synaptic factors. J. Neurophysiol. 51, 1011-1127.

Hallermann, S., Fejtova, A., Schmidt, H., Weyhersmüller, A., Silver, R. A., Gundelfinger, E. D., et al. (2010). Bassoon speeds vesicle reloading at a central excitatory synapse. Neuron 68, 710-723. doi: 10.1016/j.neuron.2010.10.026

Hille, B. (2001). Ion Channels of Excitable Membranes (Sinauer). Washington, DC: University Of Washington.

Imig, C., Min, S.-W., Krinner, S., Arancillo, M., Rosenmund, C., Südhof, T. C., et al. (2014). The morphological and molecular nature of synaptic vesicle priming at presynaptic active zones. Neuron 84, 416-431. doi: 10.1016/j.neuron.2014. 10.009

Jackman, S. L., and Regehr, W. G. (2017). The mechanisms and functions of synaptic facilitation. Neuron 94, 447-464. doi: 10.1016/j.neuron.2017. 02.047
Jackman, S. L., Turecek, J., Belinsky, J. E., and Regehr, W. G. (2016). The calcium sensor synaptotagmin 7 is required for synaptic facilitation. Nature 529, 88-91. doi: $10.1038 /$ nature 16507

Jones, B. L., and Smith, S. M. (2016). Calcium-sensing receptor: a key target for extracellular calcium signaling in neurons. Front. Physiol. 7:116. doi: 10.3389/ fphys.2016.00116

Junge, H. J., Rhee, J.-S., Jahn, O., Varoqueaux, F., Spiess, J., Waxham, M. N., et al. (2004). Calmodulin and Munc13 Form a Ca2+ sensor/effector complex that controls short-term synaptic plasticity. Cell 118, 389-401.

Kaeser-Woo, Y. J., Younts, T. J., Yang, X., Zhou, P., Wu, D., Castillo, P. E., et al. (2013). Synaptotagmin-12 phosphorylation by cAMP-dependent protein kinase is essential for hippocampal mossy fiber LTP. J. Neurosci. 33, 9769-9780. doi: 10.1523/JNEUROSCI.5814-12.2013

Kamiya, H., Ozawa, S., and Manabe, T. (2002). Kainate receptor-dependent shortterm plasticity of presynaptic ca2+ influx at the hippocampal mossy fiber synapses. J. Neurosci. 22, 9237-9243. doi: 10.1523/jneurosci.22-21-09237.2002

Kamiya, H., Shinozaki, H., and Yamamoto, C. (1996). Activation of metabotropic glutamate receptor type $2 / 3$ suppresses transmission at rat hippocampal mossy fibre synapses. J. Physiol. 493, 447-455. doi: 10.1113/jphysiol.1996.sp02 1395

Klausnitzer, J., and Manahan-Vaughan, D. (2008). Frequency facilitation at mossy fiber-CA3 synapses of freely behaving rats is regulated by adenosine A1 receptors. J. Neurosci. 28, 4836-4840. doi: 10.1523/JNEUROSCI.3729-07.2008

Körber, C., Horstmann, H., Venkataramani, V., Herrmannsdörfer, F., Kremer, T., Kaiser, M., et al. (2015). Modulation of presynaptic release probability by the vertebrate-specific protein mover. Neuron 87, 521-533. doi: 10.1016/j.neuron. 2015.07.001

Kremer, T., Kempf, C., Wittenmayer, N., Nawrotzki, R., Kuner, T., Kirsch, J., et al. (2007). Mover is a novel vertebrate-specific presynaptic protein with differential distribution at subsets of CNS synapses. FEBS Lett. 581, 4727-4733. doi: 10.1016/j.febslet.2007.08.070

Kwon, H.-B., and Castillo, P. E. (2008a). Long-term potentiation selectively expressed by nmda receptors at hippocampal mossy fiber synapses. Neuron 57 , 108-120. doi: 10.1016/j.neuron.2007.11.024

Kwon, H.-B., and Castillo, P. E. (2008b). Role of glutamate autoreceptors at hippocampal mossy fiber synapses. Neuron 60, 1082-1094. doi: 10.1016/j. neuron.2008.10.045

Lauri, S. E., Bortolotto, Z. A., Nistico, R., Bleakman, D., Ornstein, P. L., Lodge, D., et al. (2003). A role for $\mathrm{Ca} 2+$ stores in kainate receptor-dependent synaptic facilitation and LTP at mossy fiber synapses in the hippocampus. Neuron 39, 327-341. doi: 10.1016/s0896-6273(03)00369-6

Lauri, S. E., Delany, C., Clarke, J. V. R., Bortolotto, Z. A., Ornstein, P. L., Isaac, T. R. J., et al. (2001). Synaptic activation of a presynaptic kainate receptor facilitates AMPA receptor-mediated synaptic transmission at hippocampal mossy fibre synapses. Neuropharmacology 41, 907-915. doi: 10.1016/s00283908(01)00152-6

Ma, Z., Siebert, A. P., Cheung, K.-H., Lee, R. J., Johnson, B., Cohen, A. S., et al. (2012). Calcium homeostasis modulator 1 (CALHM1) is the pore-forming subunit of an ion channel that mediates extracellular $\mathrm{Ca} 2+$ regulation of neuronal excitability. Proc. Natl. Acad. Sci. US.A. 109, E1963-E1971. doi: 10. 1073/pnas.1204023109

Mendoza Schulz, A., Jing, Z., María Sánchez Caro, J., Wetzel, F., Dresbach, T., Strenzke, N., et al. (2014). Bassoon-disruption slows vesicle replenishment and induces homeostatic plasticity at a CNS synapse. EMBO J. 1-16.

Moore, K. A., Nicoll, R. A., and Schmitz, D. (2003). Adenosine gates synaptic plasticity at hippocampal mossy fiber synapses. Proc. Natl. Acad. Sci. U.S.A. 100, 14397-14402. doi: 10.1073/pnas.1835831100

Mori-Kawakami, F., Kobayashi, K., and Takahashi, T. (2003). Developmental decrease in synaptic facilitation at the mouse hippocampal mossy fibre synapse. J. Physiol. 553, 37-48. doi: 10.1113/jphysiol.2003.045948

Motulsky, H. J., and Christopoulos, A. (2003). Fitting Models to Biological Data Using Linear and Nonlinear Regression. San Diego, CA: GraphPad Software, Inc. Mukherjee, K., Yang, X., Gerber, S. H., Kwon, H.-B., Ho, A., Castillo, P. E., et al. (2010). Piccolo and bassoon maintain synaptic vesicle clustering without directly participating in vesicle exocytosis. Proc. Natl. Acad. Sci. USA 107, 6504-6509. doi: 10.1073/pnas.1002307107

Nicoll, R. A., and Schmitz, D. (2005). Synaptic plasticity at hippocampal mossy fibre synapses. Nat. Rev. Neurosci. 6, 863-876. doi: 10.1038/nrn1786 
Nowak, L., Bregestovski, P., Ascher, P., Herbet, A., and Prochiantz, A. (1984). Magnesium gates glutamate-activated channels in mouse central neurones. Nature 307, 462-465. doi: 10.1038/307462a 0

Okerlund, N. D., Schneider, K., Leal-Ortiz, S., Montenegro-Venegas, C., Kim, S. A., Garner, L. C., et al. (2017). Bassoon controls presynaptic autophagy through Atg5. Neuron 93:897-913.e7. doi: 10.1016/j.neuron.2017.01.026

Parthier, D., Kuner, T., and Körber, C. (2018). The presynaptic scaffolding protein Piccolo organizes the readily releasable pool at the calyx of Held. J. Physiol. 596, 1485-1499. doi: 10.1113/JP274885

Regehr, W. G., Delaney, K. R., and Tank, D. W. (1994). The role of presynaptic calcium in short-term enhancement at the hippocampal mossy fiber synapse. J. Neurosci. 14, 523-537. doi: 10.1523/jneurosci.14-02-00523.1994

Rodríguez-Moreno, A., and Sihra, T. S. (2004). Presynaptic kainate receptor facilitation of glutamate release involves protein kinase $a$ in the rat hippocampus. J. Physiol. 557, 733-745. doi: 10.1113/jphysiol.2004.065029

Rozov, A., and Burnashev, N. (1999). Polyamine-dependent facilitation of postsynaptic AMPA receptors counteracts paired-pulse depression. Nature 401, 594-598. doi: 10.1038/44151

Salin, P. A., Scanziani, M., Malenka, R. C., and Nicoll, R. A. (1996). Distinct shortterm plasticity at two excitatory synapses in the hippocampus. Proc. Natl. Acad. Sci. U.S.A. 93, 13304-13309. doi: 10.1073/pnas.93.23.13304

Santarelli, V. P., Eastwood, A. L., Dougherty, D. A., Ahern, C. A., and Horn, R. (2007). Calcium block of single sodium channels: role of a pore-lining aromatic residue. Biophys. J. 93, 2341-2349. doi: 10.1529/biophysj.107.106856

Schmitz, D., Mellor, J., and Nicoll, R. A. (2001). Presynaptic kainate receptor mediation of frequency facilitation at hippocampal mossy fiber synapses. Science 291, 1972-1976. doi: 10.1126/science. 1057105

Schoch, S., and Gundelfinger, E. D. (2006). Molecular organization of the presynaptic active zone. Cell Tissue Res. 326, 379-391. doi: 10.1007/s00441006-0244-y

Scott, R., Lalic, T., Kullmann, D. M., Capogna, M., and Rusakov, D. A. (2008). Target-cell specificity of kainate autoreceptor and Ca2+-Store-dependent shortterm plasticity at hippocampal mossy fiber synapses. J. Neurosci. 28, 1313913149. doi: 10.1523/JNEUROSCI.2932-08.2008

Scott, R., and Rusakov, D. A. (2006). Main determinants of presynaptic Ca2+ dynamics at individual mossy fiber-CA3 pyramidal cell synapses. J. Neurosci. 26, 7071-7081. doi: 10.1523/jneurosci.0946-06.2006

Sihra, T. S., and Rodríguez-Moreno, A. (2013). Presynaptic kainate receptormediated bidirectional modulatory actions: mechanisms. Neurochem. Int. 62, 982-987. doi: 10.1016/j.neuint.2013.03.012

Südhof, T. C. (2012). The presynaptic active zone. Neuron 75, 11-25. doi: 10.1016/ j.neuron.2012.06.012

Südhof, T. C. (2013). A molecular machine for neurotransmitter release: synaptotagmin and beyond. Nat. Med. 19, 1227-1231. doi: 10.1038/nm.3338

tom Dieck, S., Sanmartí-Vila, L., Langnaese, K., Richter, K., Kindler, S., Soyke, A., et al. (1998). Bassoon, a novel zinc-finger CAG/glutamine-repeat protein selectively localized at the active zone of presynaptic nerve terminals. J. Cell Biol. 142, 499-509. doi: 10.1083/jcb.142.2.499

Toth, K., Suares, G., Lawrence, J. J., Philips-Tansey, E., and McBain, C. J. (2000). Differential mechanisms of transmission at three types of mossy fiber synapse. J. Neurosci. 20, 8279-8289. doi: 10.1523/jneurosci.20-22-08279.2000

Traub, R. D., Miles, R., and Jefferys, J. G. (1993). Synaptic and intrinsic conductances shape picrotoxin-induced synchronized after-discharges in the guinea-pig hippocampal slice. J. Physiol. 461, 525-547. doi: 10.1113/jphysiol. 1993.sp019527
Tzounopoulos, T., Janz, R., Südhof, T. C., Nicoll, R. A., and Malenka, R. C. (1998). A role for cAMP in long-term depression at hippocampal mossy fiber synapses. Neuron 21, 837-845. doi: 10.1016/s0896-6273(00)80599-1

Varoqueaux, F., Sigler, A., Rhee, J.-S., Brose, N., Enk, C., Reim, K., et al. (2002). Total arrest of spontaneous and evoked synaptic transmission but normal synaptogenesis in the absence of munc13-mediated vesicle priming. Proc. Natl. Acad. Sci. U.S.A. 99, 9037-9042. doi: 10.1073/pnas.122623799

Villacres, E. C., Wong, S. T., Chavkin, C., and Storm, D. R. (1998). Type I adenylyl cyclase mutant mice have impaired mossy fiber long-term potentiation. J. Neurosci. 18, 3186-3194. doi: 10.1523/jneurosci.18-09-0318 6.1998

Viotti, J. S., Ott, F. W., Schleicher, E. M., Wagner, J. M., Bouter, Y., Bayer, T. A., et al. (2019). Increased Synaptic Facilitation and Exploratory Behavior in Mice Lacking the Presynaptic Protein Mover. BioRxiv. [Preprint]. doi: 10.1101/ 560896

Vyleta, N. P., Borges-Merjane, C., and Jonas, P. (2016). Plasticity-dependent, full detonation at hippocampal mossy fiber-CA3 pyramidal neuron synapses. Elife 5, 355-405. doi: 10.7554/eLife.17977

Vyleta, N. P., and Jonas, P. (2014). Loose coupling between Ca2+ channels and release sensors at a plastic hippocampal synapse. Science 343, 665-670. doi: $10.1126 /$ science. 1244811

Waites, C. L., Leal-Ortiz, S. A., Okerlund, N., Dalke, H., Fejtova, A., Altrock, W. D., et al. (2013). Bassoon and Piccolo maintain synapse integrity by regulating protein ubiquitination and degradation. EMBO J. 32, 954-969. doi: 10.1038/ emboj.2013.27

Wallrafen, R., and Dresbach, T. (2018). The presynaptic protein mover is differentially expressed across brain areas and synapse types. Front. Neuroanat. 12:58. doi: 10.3389/fnana.2018.00058

Wang, H., Pineda, V. V., Chan, G. C. K., Wong, S. T., Muglia, L. J., and Storm, D. R. (2003). Type 8 adenylyl cyclase is targeted to excitatory synapses and required for mossy fiber long-term potentiation. J. Neurosci. 23, 9710-9718. doi: 10.1523/jneurosci.23-30-09710.2003

Wang, X., Kibschull, M., Laue, M. M., Lichte, B., Petrasch-Parwez, E., and Kilimann, M. W. (1999). Aczonin, a 550-kD putative scaffolding protein of presynaptic active zones, shares homology regions with rim and bassoon and binds profilin. J. Cell Biol. 147, 151-162. doi: 10.1083/jcb.147.1.151

Weisskopf, M. G., Castillo, P. E., Zalutsky, R. A., and Nicoll, R. A. (1994). Mediation of hippocampal mossy fiber long-term potentiation by cyclic AMP. Science 265, 1878-1882. doi: 10.1126/science.7916482

Weisskopf, M. G., and Nicoll, R. A. (1995). Presynaptic changes during mossy fibre LTP revealed by NMDA receptor-mediated synaptic responses. Nature 376, 256-259. doi: 10.1038/376256a 0

Zucker, R. S., and Regehr, W. G. (2002). Short-term synaptic plasticity. Annu. Rev. Physiol. 64, 355-405.

Conflict of Interest: The authors declare that the research was conducted in the absence of any commercial or financial relationships that could be construed as a potential conflict of interest.

Copyright (®) 2019 Viotti and Dresbach. This is an open-access article distributed under the terms of the Creative Commons Attribution License (CC BY). The use, distribution or reproduction in other forums is permitted, provided the original author(s) and the copyright owner(s) are credited and that the original publication in this journal is cited, in accordance with accepted academic practice. No use, distribution or reproduction is permitted which does not comply with these terms. 